\title{
SELF ADJUSTMENT MAHASISWA PASCASARJANA DENGAN CEREBRAL PALSY
}

\section{SELF ADJUSTMENT OF POSTGRADUATE STUDENTS WITH CEREBRAL PALSY}

\author{
Mabid Barokah \\ Universitas Islam Negeri Sunan Kalijaga Yogyakarta \\ mabidbarokah26@gmail.com
}

Received: $12^{\text {th }}$ October 2020; Revised: $21^{\text {st }}$ Januari 2020; Accepted: $2^{\text {nd }}$ February 2021

\begin{abstract}
The limitation of cerebal palsy students with movement disorders and body posture makes motivators take master studies. This study aims to explore the experience of two students with cerebral palsy in their midst to lack of understanding to learn lessons, do assignments, presentations and discussions. This study uses a case study design. The subjects were cerebral palsy students who sat in the second semester as indicators of learning processes. The results of the study describe that the ability of students of cerebral palsy in adopting is characterized by their ability to overcome the difficulties experienced during the lecture process by asking for assistance of a companion when it is their turn to present or discuss and also using a method of making a dominant slide that is visual in order to reduce speaking. The limitations of speaking are adjusted by involving the companion to read and understand through writing that is conveyed in the learning that goes through. Physical limitations to walk the adjustment assisted by his personal assistant to help as transportation.
\end{abstract}

Keywords: cerebral palsy, self adjusment, physical limitations, limited speech

\begin{abstract}
ABSTRAK
Keterbatasan mahasiswa cerebal palsy dengan gangguan gerakan dan postur tubuh menjadikan motivator dalam menempuh studi magister. Penelitian ini bertujuan untuk mengeksplorasi pengalaman dua orang mahasiswa cerebral palsy dalam beradptasi di tengah kekurangan dirinya untuk memahami pelajaran, mengerjakan tugas, presentasi dan diskusi. Penelitian ini menggunakan rancangan studi kasus. Subjek penelitian adalah mahasiswa cerebral palsy yang duduk disemester dua sebagai indikator telah mengalami proses pembelajaan. Hasil penelitian mendeskripsikan bahwa kemampuan mahasiswa cerebral palsy dalam beradptasi ditandai dengan kemampuan mereka mengatasi kesulitan-kesulitan yang dialami selama proses perkuliahan dengan cara meminta bantuan pendamping ketika mendapat giliran presentasi atau berdiskusi dan juga menggunakan cara pembuatan slide yang dominan bersifat visual agar mengurangi dalam berbicara. Keterbatasan berbicara dilakukan penyesuaian diri dengan melibatan pendamping untuk membacakan serta memahami melalui tulisan yang disampaikan dalam pembelajaran yang dilaluinya. Keterbatasan fisik untuk berjalan penyesuaian diri dibantu oleh asisten pribadinya untuk membantu sebagai transportasinya.
\end{abstract}

Kata kunci : cerebral palsy, self adjusment, keterbatasan fisik, keterbatasan berbicara 


\section{PENDAHULUAN}

Self adjusment atau dikenal dengan penyesuaian diri merupakan aspek yang paling penting dalam kehidupan seseorang. Individu yang dapat menyesuaikan diri dengan baik maka akan memperoleh kebahagiaan, kemandirian dan keharmonisan dalam diri mereka. Penyesuaian diri berarti upaya mengubah diri sendiri agar sesuai dengan lingkungan dan mengubah lingkungan agar sesuai dengan diri sendiri (Rafikayati, Badian, Soedarmadji, 2018).

Penyesuaian diri merupakan kemampuan individu meleburkan diri dalam lingkungan yang dihadapinya (Walgito, 2004). Self adjustment adalah kemampuan seseorang untuk mereaksi kenyataan-kenyataan, situasi-situasi, hubungan-hubungan sosial dalam lingkungannya guna memenuhi kebutuhan-kebutuhan hidup sesuai dengan nilai-nilai dan norma-norma yang berlaku. (Wijaya, 2015)

Penyesuaian diri adalah suatu proses untuk memenuhi kebutuhan internal dan eksternal individu yang melibatkan respon-respon mental dan tingkah laku yang mendorong seseorang untuk menyesuaikan diri terhadap lingkungan (Patil SP, Patil PB, Kashetty, 2014). Secara spesifik penyesuaian diri dapat diartikan sebagai usaha individu dalam memenuhi tuntutan lingkungan fisik dan sosialnya, apabila individu tidak mampu memenuhi maka akan timbul perasaan tidak tenang dan menimbulkan gangguan keseimbangan, sebaliknya apabila individu berhasil menyesuaikan diri sesuai dengan tuntutan lingkungan psikologis maka akan menimbulkan perasaan puas,superior dan menumbuhkan rasa percaya diri.

Secara umum, sesorang yang berkebutuhan khusus diartikan sebagai individu yang mengalami hambatan dalam proses pembelajaran karena terhambat oleh keadaan fisik, gangguan mental, ganguan emosi, gangguan sosial, komunikasi, memiliki kecerdasan dan bakat khusus. 
Berkebutuhan khusus itu banyak macamnya, salah satunya ialah Cerebral Palsy atau yang dikenal dengan nama CP yaitu keadaan kerusakan jaringan otak yang permanen dan tidak progresif yang terjadi pada waktu masih muda (sejak dilahirkan) dan merintangi perkembangan otak normal dengan gambaran klinis yang menunjukan kelainan dalam sikap dan pergerakan disertai kelainan neurologis berupa kelumpuhan spastik dan kelainan mental. Istilah cerebral palsy merupakan istilah yang digunakan untuk menggambarkan sekelompok gangguan gerakan, postur tubuh, dan tonus yang bersifat non progresif, kronis dan akibat cedera pada sistem saraf pusat selama awal masa perkembangan (Arief M, 2003; Johnston MV, 2007) dalam ”(Utomo AHP 2013).

Cerebral palsy sendiri merupakan suatu gangguan atau kelainan yang terjadi selama perkembangan anak, yang merusak sel-sel motorik dalam susunan syaraf pusat, akibat kelainan pada otak anak. Clark mengatakan. cerebral palsy merupakan suatu keadaan kerusakan jaringan otak pada pusat motorik atau jaringan penghubungnya, yang terjadi pada masa prenatal, saat persalinan atau selama proses pembentukan syaraf pusat, ditandai dengan adanya paralisis, paresis, gangguan kordinasi atau kelainan fungsi motorik.(Sriwidodo, Untung \& Haryanto 2010).

Cerebral palsy (CP) adalah istilah yang digunakan bagi semua gangguan neurologik kronik yang berwujud gangguan control gerakan, muncul pada awal kehidupan, dengan latar belakang penyakit yang non progresif. Gangguan neurologik ini menyebabkan cacat menetap.(Hartono 2004) Sigmund Freud menyebutkan kelainan ini dengan istilah "Infantil Cerebral Paralysis". Sedangkan Sir William Osler adalah yang pertama kali memperkenalkan istilah "Cerebral palsy". Nama lainnya adalah "Static Encephalopathies of Childhood" (Soetjiningsih, 1995)

Dapat disimpulkan bahwa Cerebral Palsy (CP) adalah suatu kondisi terganggunya fungsi otak dan jaringan saraf yang mengendalikan gerakan, pendengaran, penglihatan, dan kemampuan berpikir. Yang ditandai oleh adanya kelainan gerak, sikap atau bentuk tubuh, gangguan koordinasi, yang terkadang disertai juga dengan gangguan psikologis dan sensoris yang disebabkan oleh adanya kerusakan atau kecacatan pada masa perkembangan otak. 
Cerebral Palsy terbagi menjadi beberapa jenis yaitu spastic, athetoid, dan ataxic.Selain itu, juga ada berkategori ringan, sedang dan berat. Seseorang yang mengalami celebral palsy akan mengalami kendala atau gangguan dibagian tertentu diantaranya: 1) memiliki cacat kognitif, atau cacat intelektual. Kecacatan ini paling sering terjadi pada penderita quadriplegia spastik, di mana beberapa anggota tubuhnya terpengaruh. Mereka yang memiliki kondisi gabungan cerebral palsy dan epilepsi berisiko tinggi memiliki kecacatan intelektual dan ketidakmampuan belajar. 2)

Menurut Cerebral Palsy Foundation, sekitar 1 dari 10 orang dengan cerebral palsy memiliki gangguan penglihatan. Lalu, 1 dari 25 orang CP memiliki masalah pendengaran yang parah.Masalah penglihatan mungkin akan berisiko menimbulkan mata juling. Di mana mata juling dapat memengaruhi kemampuan mata untuk mengetahui seberapa jauh atau dekat sesuatu yang dilihat. Apabila masalah penglihatannya sekadar mata kabur, mata minus, dan silinder, pakai kacamata atau kontak lensa kemungkinan dapat memperbaiki kondisi ini. Sedangkan penyakit kuning atau ketika orang dengan CP mengalami kekurangan oksigen di otak saat proses persalinan, hal ini dapat menyebabkan gangguan pendengaran parsial hingga tuli.3) Komplikasi orang dengan cerebral palsy bisa mengakibatkan dirinya tidak mampu untuk mengendalikan beberapa otot tertentu. Umumnya otot seperti seperti otot bibir, rahang, tenggorokan, dan lidah.Di mana sering kali menyebabkan orang dengan CP tidak bisa menahan air liur mereka, sulit mengunyah, dan sulit menelan. Masalah-masalah ini seringkali mengganggu kemampuan mereka untuk makan makanan sehat dan berisiko kekurangan gizi (Joseph, 2019)

Seseorang yang mengalami cerebral palsy, tentu akan mempunyai kendala atau kesulitan dalam berinteraksi dan penyesuaian dalam proses pembelajaran. Terlebih pada tingkat magister, beban mata kuliah dan tugas jauh lebih berat dan banyak. Selain itu, mahasiswa magister dituntut memiliki kemampuan analisis dan kebanyakan tugas yang diberikan dosen bersifat individu. Bagi mahasiswa yang mengalami CP atau cerebral palsy butuh penyesuaian diri dan kerja keras yang ektra untuk memenuhi standar perkuliahan yang ditawarkan oleh setiap universitas. 
Oleh karena itu, penulis ingin melakukan penelitian mendalam mengenai self adjusment pada mahasiswa pascasarjana cerebral palsy, yang mana penulis ingin mengetahui bagaimana mereka meyesuaikan diri dalam mengikuti proses perkuliahan mulai dari mengerjakan tugas individu,presentasi, menjawab pertanyaan, dan memahami pelajaran. Terlebih mereka yang mengalami kesulitan dalam berbicara,bagaimana mereka mengatasi hal tersebut ketika mendapat giliran presentasi, apakah mereka diberikan tugas khusus dari dosen yang berbeda dengan mahasiswa normal lainnya. Selain itu, belum ada yang mengangkat masalah ini secara khusus, melainkan lebih kepada penerimaan diri dan subjek yang berbeda.

\section{METODE PENELITIAN}

Metode yang digunakan dalam artikel ini ialah menggunakan rancangan studi kasus atau case study, dapat dijelaskan sebagai suatu metode penelitian yang dikehendaki untuk melacak peristiwaperistiwa kontemporer (Listiani \& Savira, 2015).

Subjek penelitian ini berjumlah dua orang mahasiswi magister cerebral palsy dengan universitas yang berbeda yaitu UIN Sunan Kalijaga dan UNY Yogyakarta. Penelitian ini menggunakan purposive sampling untuk pengambilan subjek penelitian, dimana pengambilan sampel didasarkan pada kriteria tertentu yaitu: 1). Mahasiswa cerebral palsy. 2) Masuk dalam klasifikasi derajat kelainan cerebral palsy golongan ringan sampai sedang. 3) Mampu berkomunikasi dengan cukup baik. 4). Bersedia menjadi partisipan penelitian.

Teknik pengumpulan data dilakukan menggunakan teknik wawancara semi terstruktur, dimana pelaksananya lebih bebas dan partisipan lebih terbuka dalam memberikan informasi, sehingga data yang didapat lebih dalam. Teknik analisis data yang digunakan dalam penelitian ini adalah analisis tematik. Analisis tematik adalah metode yang digunakan untuk mengidentifikasi, menganalisis, dan melaporkan pola-pola tema di dalam data (Braun \& Clarke, 2006 dalam Listiani \& Savira 2015). 
Metode ini bisa digunakan peneliti untuk berfokus pada analisis rinci dari aspek-aspek tertentu dari data yang paling relevan dengan pertanyaan penelitian atau memberikan deskripsi yang kaya terhadap data secara keseluruhan. Analisis tematik ini memungkinkan peneliti untuk terlibat dengan teori untuk mendapatkan analisis data yang lebih mendalam.

\section{HASIL PENELITIAN}

Hasil penelitian ini merupakan rangkuman dari hasil wawancara yang dilakukan dengan informan. Informan dalam penelitian ini adalah dua orang mahasiswi cerebral palsy tipe spastik. Adapun data umum para informan tersedia di tabel 1 dengan nama sengaja disamarkan karena pertimbangan etis.

Tabel 1. Ringkasan Profil Narasumber

\begin{tabular}{|c|c|c|c|c|c|c|c|c|}
\hline No & Inisial & JK & Alamat & Usia & $\begin{array}{c}\text { Riwayat } \\
\text { CP }\end{array}$ & $\begin{array}{l}\text { Tipe } \\
\text { CP }\end{array}$ & Keluhan & Tempat Kuliah \\
\hline 1. & APP & $\mathrm{P}$ & Bantul & 27 & Sejak lahir & Spastik & $\begin{array}{l}\text { Kelumpuhan } \\
\text { pada kaki, } \\
\text { cacat tangan } \\
\text { kanan dan } \\
\text { sedikit } \\
\text { kesulitan } \\
\text { bicara }\end{array}$ & UNY \\
\hline 2. & DAP & $P$ & Yogya & 26 & Sejak lahir & $\begin{array}{l}\text { Spastik } \\
\qquad \& \\
\text { athetoid }\end{array}$ & $\begin{array}{l}\text { Kesulitan } \\
\text { bicara dan } \\
\text { kekauan pada } \\
\text { otot leher }\end{array}$ & $\begin{array}{c}\text { UIN SUNAN } \\
\text { KALIJAGA } \\
\text { YOGYAKARYTA }\end{array}$ \\
\hline
\end{tabular}

\section{Hasil Wawancara Subjek 1}

Narasumber pertama yang berinisial AAP merupakan kelahiran tahun 1992. APP merupakan anak pertama dari dua bersaudara. APP adalah mahasiswi UNY yang saat ini menempuh studi magister semester tiga jurusan linguistik. AAP mempunyai hobi menulis puisi dan memiliki kemampuan berbahasa Inggris yang baik. APP bercita-cita menjadi seorang guru dan penerjemah 
yang handal. APP mengalami cerebral palsy jenis spastik yang mana kekauan pada otot-otot kaki dan tangan sebelah kanan sehingga sulit untuk bergerak dan harus menggunakan kursi roda untuk pergi ke kampus. Selain itu, sedikit kesulitan dalam bicara yang mana harus dengan cara menarik nafas yang panjang dan cepat lelah.

Dalam menempuh studi magister, saudari APP butuh waktu satu semester untuk menyesuaikan diri dengan lingkungan kampus, teman, dosen maupun tugas-tugas yang diberikan. Terlebih jika mendapat ruangan kelas dilantai atas, APP selalu didampingi asistennya untuk membantu mendorong kursi roda dan mengantarnnya ke kelas, perpustakaan dan lain sebagainya. Dalam satu kelas berisikan 20 orang termasuk dari orang luar negeri, yang mana hanya APP yang merupakan mahasiswi satu-satunya yang mengalami CP dalam kelas tersebut.

Dalam kondisi seperti ini, APP harus kerja ektra untuk menempuh tugas-tugas yang diberikan karena tugas yang diberikan berlaku adil dan tidak dibedakan. "Dosen juga tidak memberikan waktu tambahan “, gumamnya. Karna keterbatasan fisikk, APP harus mengerjakan tugas kuliah jauh-jauh hari karena untuk mengetik butuh waktu yang lama. Jika mendapat giliran presentasi, untuk mensiasati keterbatasan dalam berbicara yang tidak bisa terlalu lama dan tertekan, APP membuat PPT dengan memperbanyak slide yang berbentuk visualisasi. Penelti melihat secara langsung pada saat wawancara, narasumber sedikit kesulitan dan mudah lelah dalam berbicara. Jika percakapan agak panjang, semakin lama tubuhnya hampir jatuh kebelakang dan seperti kehabisan nafas.

Untuk mencari literatur di perpustakaan,APP sedikit mengalami kesulitan terutama untuk mengambil buku di rak yang tinggi, sehingga harus meminta bantuan orang-orang yang ada disekitar. Dalam menangkap pelajaran APP tidak mengalami hambatan, tetapi sama seperti anak normal lainnya. Jika kurang paham, dia mencari buku yang berkaitan atau bertanya langsung kepada dosen. Dari hasil wawancara, APP merupakan mahasiswi yang cerdas, dibuktikan dengan menjadi wisudawati tercepat dan terbaik serta menjadi pembicara disuatu acara. Selain itu, juga 
sering diminta menjadi penerjemah bahasa inggris. Saat ini, APP juga sudah selesai seminar proposal dan menerbitkan satu jurnal.

Adapun metode belajarnya ialah dengan meringkas pelajaran dan mengerjakan tugas dari jauh hari sebelumnya. Hal yang menjadi motivasi APP melanjutkan studi magister ialah dukungan orangtua. "Sebenarnya bagi saya S1 saja sudah cukup, namun karena orang tua saya mengatakan saya mampu dan bisa untuk terus kuliah, akhirnya saya melanjutkan studi lagi” (W.APP 3-5).

Selain orangtua,yang membuat APP termotivasi ialah sosok Mbak Saprina yang dengan kondisi CP tapi sudah menjadi PNS. Selain itu, juga support dari teman-teman S1nya dan adanya permintaan dari orang-orang untuk menterjemahkan yang membuat APP merasa dipercaya dan bisa diandalkan. Adapun hubungan APP dengan teman kelas, sangat bagus dikarenakan teman-temannya baik dan peka terhadap APP jika membutuhkan bantuan. Telebih orang luar negeri tanpa diminta, mereka peka dengan sendirinya. Malahan APP mengatakan, dosennya yang kadang membully dengan mengatakan sakit apa atau kenapa pakai kursi roda. Walaupun kadang kesal, APP hanya tersenyum dan menganggap itu hanya karena tidak tahu saja.

Adapun, harapan APP setelah lulus ialah dapat berkarir menjadi guru serta menjadi penerjemah yang handal. Di akhir wawancara, APP juga berpesan untuk seluruh mahasiwa agar lebih memanfaatkan waktu dan tubuh yang sehat dalam mengerjakan kewajiban yang diberikan.

\section{Hasil Wawancara Subjek 2}

Narasumber kedua dengan inisial DAP merupakan mahasiswi pascasarjana UIN Sunan Kalijaga konsentrasi Studi Disabilitas dan Pendidikan Inklusi Semester 2. DAP merupakan anak kedua dari 3 bersaudara. DAP ini mempunyai hobi makan dan jalan. Selain itu, juga aktif berorganisasi di difabel dari tahun 2017 awal. DAP mengalami cerebral palsy sejak lahir dengan jenis spastik dan athetoid level 1 yaitu kekauan otot pada leher dan kesulitan pada berbicara. Sehingga butuh tenaga ekstra untuk berkomunikasi. Peneliti melihat pada saat wawancara, 
bagaimana narasumber berusaha berkomunikasi, dibanding dengan narasumber pertama, DAP ini lebih sulit untuk mengontrol nafas dan berbicara jelas. Hal ini merupakan salah satu hambatan yang dialami DAP dalam proses perkuliahan.

Dari hasil wawancara, ternyata untuk angkatan DAP pada konsentrasi studi disabilitas dan pendidikan inklusi hanya berjumlah dua orang. Yang mana satu kelas dengan mahasiswi tunarungu.Namun pada semester ganjil ini, mereka digabung dengan kelas lain dan dengan mahasiswa normal. Sehingga punya tantangan baru dalam mengikuti proses perkuliahan. DAP mengaku mengalami banyak kesulitan pada semester ini terutama ketika mendapat giliran presentasi. Dengan kondisi kesulitan dalam berbicara, DAP harus menggunakan pendamping ketika harus presentasi dan kuliah gabungan.

Tugas-tugas yang diberikan dosen pun berlaku adil untuk semua tanpa ada pengecualian. Sehingga DAP harus mnegerjakan tugas dengan ekstra dan membuat makalah dan PPT seperti biasanya. Ketika presentasi, DAP meminta bantuan pendamping untuk menyampaikan materi. Ketika diskusi tanya jawab, DAP menulis jawabannya dan meminta pendamping yang menyampaikannya. Ketika DAP yang ingin bertanya, ia meminta bantuan teman untuk membacakannya.

DAP mengaku merasa kesulitan ketika pertama kali masuk perkuliahan pascasarjana. Karena jurusan yang diambil tidak linear dengan S1, sehingga tidak tahu sama sekali tentang pengetahuan atau ilmu-ilmu yang berkaitan dengan studi yang diambilnya. Oleh karena itu, harus belajar dari nol dan lebih ekstra. Terlebih kadang ada dosen yang kurang memahami apa yang dibicarakan DAP. Sehingga sulit untuk berkomunikasi langsung.

Dalam belajar, DAP sedikit sulit memahami ketika materi yang dipelajari tergolong susah dan ketika sedang banyak pikiran. Dalam mengerjakan tugas individu, kesulitan yang dihadapi ialah ketika mencari referensi yang begitu banyak dan dalam berbahasa inggris, jadi harus diterjemahkan terlebih dahulu. Dalam aspek menyesuaikan diri dalam proses perkuliahan, DAP sampai sekarang 
masih dalam tahap penyesuaian baik mengenal karakter dosen, teman-teman dan mata kuliah baru. Dengan adanya tuntutan dalam menempuh studi ini, DAP kadang merasa capek, bingung karena perbedaan dengan S1 dulu sangat jauh berbeda.

Dalam belajar, metode yang digunakan oleh DAP ialah metode belajar kinetik dominan. Adapun hal yang membuat motivasi dalam menempuh studi magister ialah orang tua, adik dan teman-teman seperjuangan yang disabilitas. DAP juga mempunyai hubungan baik dengan teman kelasnya karena juga mensupport dan membantu DAP ketika butuh bantuan. DAP berharap setelah lulus S2 ia segera cepat mendapat pekerjaan disebuah instansi atau bisa menjadi PNS. Di akhir wawancara, DAP berpesan bahwa “ ketika kamu memberikan jalan untuk orang, insyaallah kamu akan dibukakan jalan ketika mengalami kesulitan. Selalu berbagi kasih tanpa membedakan serta jangan lupa bersyukur”. (M,DAP 7-9).

\section{DISKUSI}

\section{Adaptasi Mahasiswa Cerebral Palsy}

Individu dikatakan tidak mampu menyesuaikan diri apabila perasaan sedih, rasa kecewa, atau rasa putus asa berkembang dan mempengaruhi fungsi-fungsi fisiologi serta psikologinya. Individu menjadi tidak mampu menggunakan pikiran dan sikap dengan baik, sehingga tidak mampu mengatasi tekanan-tekanan yang muncul dengan cara yang baik. (Schneiders dalam (Renaldhi Ardhian Putra 2014, 3).

Schneiders mendefinisikan self adjustment sebagai proses belajar memahami, mengerti dan berusaha melakukan apa yang diinginkan oleh individu maupun lingkungannya yang melibatkan proses mental, respon tingkah laku, frustasi dan konflik untuk mencapai suatu keharmonisan atas tuntutan dalam dirinya dan dunia di sekitarnya.(Schneiders, A.A. 2008).

Schneiders membagi self adjustment menjadi empat unsur yaitu (a) adaptation, atau adaptasi yaitu penyesuaian yang dipandang sebagai kemampuan beradaptasi atau kemampuan 
untuk mengharmoniskan antara tingkah laku dengan lingkungannya karena orang yang melakukan penyesuaian diri dengan baik maka akan mempunyai hubungan yang memuaskan dengan lingkungannya. (b) conformity, penyesuaian diri yang sesuai dengan kriteria sosial yang berlaku, (c) mastery, artinya individu yang menyesuaikan diri, baik mempunyai kemampuan membuat rencana dan mengorganisasikan diri sehingga dapat menguasai dan menanggapi segala masalah dengan efisien.

(d) individual variation, artinya ada perbedaan individual pada perilaku dan respon individu dalam menanggapinya.(Anonim 2009) dalam Ali dan Anshori,2011,173).

Dari hasil wawancara, peneliti dengan dua narasumber yang mengalami cerebral palsy. Peneliti melihat bahwa kedua narasumber tersebut dapat menyesuaikan diri dalam menempuh studi magister baik dari mengerjakan tugas individu, presentasi dan melakukan diskusi. Keterbatasan mereka bukanlah jadi penghalang untuk bekarya dan berkarir. Mereka menyadari kekurangan mereka dengan mencari cara dan menyesuaikan diri dengan lingkungan sekitar.

Dengan adanya tuntutan dalam menempuh perkuliahan, DAP dan APP menyesuaikan diri dengan melakukan beberapa hal, Seperti yang dilakukan DAP, ia meminta bantuan pendamping ketika harus presentasi dan melakukan diskusi di kelas. Sedangkan APP dengan cara membuat slide visual ketika presentasi. Keterbatasan yang dimiliki APP dan DAP bukan suatu alasan bagi mereka untuk tidak melaksanakan tugas yang diberikan, justru sebagai tantangan mereka untuk memecahkan dan mencari cara untuk menutupi keterbatasan yang dimiliki.

Dengan kondisi seperti ini, mereka tetap dapat bekarya dan membuktikan kepada kita semua bahwa mereka jauh lebih baik dan dapat berprestasi, bekarya, mempunyai skill dan aktif berorganisasi.Seperti yang dimiliki APP yang dinobatkan sebagaikan lulusan terbaik dan penerjemah bahasa Inggris. Tak kalah, DAP juga aktif berorganisasi dan sering mengadakan acara-acara di organisasinya. 
Hal ini, mengajarkan kepada kita agar selalu bersyukur atas karunia yang diberikan Allah serta tetap semangat menghadapi suatu musibah. Selain i tu, juga lebih memanfaatkan waktu sebaik mungkin, bekarya sebanyak mungkin dan paling utama selalu menjalankan perintah Allah.

\section{Penguasaan Dorongan Emosi}

Individu dengan penyesuaian diri yang tinggi memiliki ciri-ciri antara lain: mampu beradaptasi, mampu berusaha mempertahankan diri secara fisik, mampu menguasai dorongan emosi, perilakunya menjadi terkendali dan terarah, motivasi tinggi dan sikapnya berdasarkan realitas.(Schneiders, A.A, 2008).

Hal ini termasuk pada diri APP dan DAP, yang mana mereka mampu beradaptasi dengan baik dalam proses pembelajaran yaitu semua tugas kuliah dikerjakan dengan baik. Agar tidak ketinggalan dengan teman-temannya, mereka mengerjakan tugas dari jauh hari sebelumnya. Jika menadapat giliran presentasi dan berdiskusi mereka mencari cara untuk menutupi keterbatasan mereka baik menggunakan pendamping maupun cara lainnya.

Selain itu, mereka juga mampu mempertahankan diri secara fisik walaupun memiliki keterbatasan, seperti yang dialami APP dengan keterbatasan berjalan, ia membawa asisten pribadinya untuk membantu sebagai transportasinya. Sedangkan DAP yang memiliki keterbatasan dalam berbicara, ia berkomunikasi dengan cara menulis jika lawan bicaranya tidak paham dan minta bantuan teman atau pendamping untuk membacakannya. Dipandang sebelah mata atau ejekan sudah biasa mereka terima, tetapi mereka tetap dapat menguasai dorongan emosi dan tidak berkecil hati, justru mereka bersemangat belajar dan bekarya.

Dengan adanya tuntutan di kampus, mereka berusaha menjalankan dengan maksimal dan manajemen waktu dengan baik. Walaupun dalam penyesuaian ini mereka butuh waktu. Seperti APP membutuhkan waktu satu semester untuk terbiasa dengan tugas-tugas berat, teman dan 
dosen sekelilingnya. Hal ini, juga dialami oleh DAP, terlebih jurusan yang diambil berbeda dengan sebelumya, sehingga harus belajar lebih giat dan dari nol.

\section{Dorongan Motivasi}

Ada beberapa faktor yang mendorong seseorang melakukan adjustment. Menurut Sarlito (1992) faktor-faktor tersebut meliputi:

1. Kesadaran (awarness), yaitu individu menyadari akan kondisi lingkungan yang baru sehingga dapat segera mengubah tingkah laku agar sesuai dengan lingkungannya atau mengubah lingkungannya agar sesuai dengan tingkah lakunya. Kesadaran ini terdiri atas pengetahuan, kepercayaan dan norma-norma.

2. Persepsi. Persepsi individu terhadap lingkungannya itu relative, di mana persepsi tercipta karena adanya interaksi yang terjadi antara individu beserta seluruh sifat-sifat pribadi dan pengalaman masa lampaunya dengan lingkungan di mana ia berada.

3. Konflik penerimaan dan penolakan. Karena adanya konflik penerimaan ataukah penolakan pada individu dalam lingkungannya yang baru maka individu akan terdorong untuk bertingkah laku sesuai dengan lingkungannya.

4. Motivasi. Adanya motivasi yang dirasakan individu berkenaan dengan lingkungannya membuat individu berusaha untuk melakukan adjustment.

Menurut Schneiders (1964) motivasi terbagi atas dua yaitu:

1. Conscious motivation atau motivasi yang disadari yaitu meliputi needs (kebutuhan), desires and wants (keinginan yang kuat), motives (alasan), interests (ketertarikan), attitudes (sikap), and goals (tujuan).

2. Unconscious motivation atau motivasi yang tidak disadari yaitu meliputi feelings (perasaan), experience (pengalaman), wishes (harapan), instincts (insting), habit (kebiasaan), and mechanisms (pertahanan-pertahanan diri yang lain). 
Berdasarkan teori diatas, faktor yang membuat APP dan DAP dapat menyesuaikan diri dengan baik ialah kesadaran akan kewajiban dan tuntutan dalam perkuliahan. Sehingga mereka menyadari apa yang harus dilakukan, bagaimana cara melakukannya dan kapan haru dilakukan. Semua itu, dimanajeman dengan baik dan dijalani dengan senang hati. Selain itu, hal yang membuat mereka semangat ialah dorongan dan motivasi dari orang tua dan teman. Kepercayaan dan dukungan penuh yang membuat mereka mempunyai kepercayaan diri dan semangat untuk tetap melanjutkan studi dan menjalani kehidupan dengan baik.

Selain itu, APP juga merasa bersemangat ketika ada orang yang meminta bantuan untuk menterjemahkan bahasa inggris, hal tersebut membuat APP merasa dia diperlukan dan dianggap. Sesorang yang bernama Mbak Saprina dengan kondisi CP yang sudah menjadi PNS,juga salah satu penyemangat bagi APP. Sedangkan DAP, selain orang tua, ia juga mendapat motivasi dari teman seperjuangan di organisasi inklusi.

\section{KESIMPULAN DAN SARAN}

Penyesuaian diri mahasiswa cerebral palsy ditandai dengan cara pendekatan dan mengenali lingkungan sekitar, misalnya ketika mengalami kesulitan dalam presentasi dikarenakan kondisi mereka yang sulit berbicara dan mengatur nafas. Mereka menggunakan pendamping untuk membantunya dalam menyampaikan materi presentasi dan menjawab pertanyaan-pertanyaan yang diberikan dan ada juga yang menggunakan cara membuat slide yang lebih dominan bersifat visual untuk mengurangi berbicara.

Kemampuan dalam penguasaan emosi pada mahasiswa cerebral palsy ditandai dengan semangatnya kedua narasumber ketika menghadapi kesulitan dalam mengerjakan tugas yaitu dengan mencari cara untuk menghadapinya. Dengan kekurangan yang dialami,dorongan motivasi dari keluarga dan teman merupakan pemicu utama mereka untuk tetap berkarya, berorganisasi dan berhubungan baik dengan teman, dosen dan lingkungan sekitar. 
Selain itu, mereka juga mampu mempertahankan diri secara fisik walaupun memiliki keterbatasan, seperti yang dialami APP dengan keterbatasan berjalan, ia membawa asisten pribadinya untuk membantu sebagai transportasinya. Sedangkan DAP yang memiliki keterbatasan dalam berbicara, ia berkomunikasi dengan cara menulis jika lawan bicaranya tidak paham dan minta bantuan teman atau pendamping untuk membacakannya.

\section{DAFTAR PUSTAKA}

Ana Rafikayati, Lutfi Isni Badian, Boy Soedarmadji. 2018. "The Role of Counseling Guidance Teacher for Helping Self Adjustment of Special Needs Children in Inclusion School" Advances in Social Science, Education and Humanities Research, volume 272.

Anonim. 2009. "Self-Adjustment." Https://Www.Duniapelajar.Com/2009/10/30/Self-Adjustment/ (blog). 2009.

Fitria Listiani dan Siti Ina Savira. 2015. "Penerimaan Diri Remaja Cerebral Palsy" Vol.3 No.2. Hartono. 2004. Statistik Untuk Penelitian. Yogyakarta: LSFK2P \& Pustaka Belajar.

Novita Joseph. 2019. “Apa Itu Cerebral Palsy?” Hello Sehat (blog). March 15, 2019. https://hellosehat.com/penyakit/cerebral-palsy-adalah/.

Patil SP, Patil PB, Kashetty MV. 2014. "Effectiveness of Different Tooth Brushing Techniques on the Removal of Dental Plaque in 6-8 Year Old Children of Gulbarga" J Int Soc Prev Community Dent.

Renaldhi Ardhian Putra. 2014. "Hubungan Antara Penerimaan Diri Dengan Penyesuaian Diri Pada Remaja DIfabel." Universitas Muhammadiyah Surakarta.

Sarwono, Sarlito. n.d. Psikologi Lingkungan. Jakarta: Gramedia.

Schneiders, A.A. 2008. Personal Adjusment and Mental Health. New York: Holtt.Renchart and Winston.

Soetjiningsih. 1995. Tumbuh Kembang Anak. Jakarta: Penerbit Buku Kedokteran EGC.

Sriwidodo, Untung dan Agus Budhi Haryanto. 2010. "Pengaruh Komunikasi Dan Kesejahteraan Terhadap Kinerja Pegawai Dinas Pendidikan Kabupaten Sukoharjo" Jurnal Manajemen Sumberdaya Manusia Vol. 4 No. 148 Juni.

Utomo AHP. 2013. "Cerebral Palsy Tipe Spatic Diplegy Pada Anak Usia Dua Tahun" Medula, Volume 1, Nomor 4.

Wijaya, B.O. 2015. "Hubungan Antara Penyesuaian Diri Dengan Kemandirian Pada Mahasiswa Yang Merantau Fakultas Teknik Industri Universitas Bina Darma Angkatan 2014/2015 Palembang.” Jurnal Fakultas Psikologi Universitas Bina Darma Palembang. 